\title{
Pharmacological interventions for painful sickle cell vaso- occlusive crises in adults
}

\author{
Tess E. Cooper \\ University of Oxford \\ Ian R. Hambleton \\ The University of the West Indies \\ Samir K. Ballas \\ Thomas Jefferson University \\ Philip J. Wiffen \\ University of Oxford
}

Follow this and additional works at: https://jdc.jefferson.edu/cardeza_foundation

Part of the Hematology Commons

Let us know how access to this document benefits you

\author{
Recommended Citation \\ Cooper, Tess E.; Hambleton, Ian R.; Ballas, Samir K.; and Wiffen, Philip J., "Pharmacological \\ interventions for painful sickle cell vaso-occlusive crises in adults" (2016). Cardeza Foundation \\ for Hematologic Research. Paper 35. \\ https://jdc.jefferson.edu/cardeza_foundation/35
}

This Article is brought to you for free and open access by the Jefferson Digital Commons. The Jefferson Digital Commons is a service of Thomas Jefferson University's Center for Teaching and Learning (CTL). The Commons is a showcase for Jefferson books and journals, peer-reviewed scholarly publications, unique historical collections from the University archives, and teaching tools. The Jefferson Digital Commons allows researchers and interested readers anywhere in the world to learn about and keep up to date with Jefferson scholarship. This article has been accepted for inclusion in Cardeza Foundation for Hematologic Research by an authorized administrator of the Jefferson Digital Commons. For more information, please contact: JeffersonDigitalCommons@jefferson.edu. 


\section{(E) Cochrane Library}

Cochrane Database of Systematic Reviews

\section{Pharmacological interventions for painful sickle cell vaso- occlusive crises in adults (Protocol)}

Cooper TE, Hambleton IR, Ballas SK, Wiffen PJ

Cooper TE, Hambleton IR, Ballas SK, Wiffen PJ.

Pharmacological interventions for painful sickle cell vaso-occlusive crises in adults.

Cochrane Database of Systematic Reviews 2016, Issue 5. Art. No.: CD012187.

DOI: 10.1002/14651858.CD012187.

www.cochranelibrary.com 
TABLE OF CONTENTS

HEADER . . . . . . . . . . . . . . . . . . . . . . . . . . . . . . . . . . . . 1

ABSTRACT . . . . . . . . . . . . . . . . . . . . . . . . . . . . . . . . . . . . . . . . . .

BACKGROUND . . . . . . . . . . . . . . . . . . . . . . . . . . . . . . . . . . . .

OBJECTIVES . . . . . . . . . . . . . . . . . . . . . . . . . . . . . . . . . . . . . . . . .

METHODS . . . . . . . . . . . . . . . . . . . . . . . . . . . . . . . . . . . . . . 44

ACKNOWLEDGEMENTS . . . . . . . . . . . . . . . . . . . . . . . . . . . . . . . . . . . . . . . . . .

REFERENCES . . . . . . . . . . . . . . . . . . . . . . . . . . . . . . . . . . . . . . 7

APPENDICES . . . . . . . . . . . . . . . . . . . . . . . . . . . . . . . . . . . . . 10

CONTRIBUTIONS OF AUTHORS . . . . . . . . . . . . . . . . . . . . . . . . . . . . . . . . . . . . . . .

DECLARATIONS OF INTEREST . . . . . . . . . . . . . . . . . . . . . . . . . . . . . . . . 13

SOURCES OF SUPPORT . . . . . . . . . . . . . . . . . . . . . . . . . . . . . . . . . . . . . . . . . .

Pharmacological interventions for painful sickle cell vaso-occlusive crises in adults (Protocol)

Copyright $\odot 2016$ The Cochrane Collaboration. Published by John Wiley \& Sons, Ltd. 


\title{
[Intervention Protocol]
}

\section{Pharmacological interventions for painful sickle cell vaso- occlusive crises in adults}

\author{
Tess E Cooper ${ }^{1}$, Ian R Hambleton ${ }^{2}$, Samir K Ballas ${ }^{3}$, Philip J Wiffen ${ }^{4}$ \\ ${ }^{1}$ Cochrane Pain Palliative and Supportive Care Review Group, Cochrane Collaboration, Oxford, UK. ${ }^{2}$ Chronic Disease Research \\ Centre, Tropical Medicine Research Institute, The University of the West Indies, Bridgetown, Barbados. ${ }^{3}$ Cardeza Foundation for \\ Hematologic Research, Department of Medicine, Jefferson Medical College, Thomas Jefferson University, Philadelphia, USA. ${ }^{4}$ Pain \\ Research and Nuffield Department of Clinical Neurosciences (Nuffield Division of Anaesthetics), University of Oxford, Oxford, UK \\ Contact address: Tess E Cooper, Cochrane Pain Palliative and Supportive Care Review Group, Cochrane Collaboration, Oxford Pain \\ Research, Churchill Hospital, Oxford, Oxfordshire, OX3 7LE, UK. tess.cooper@ndcn.ox.ac.uk.
}

Editorial group: Cochrane Pain, Palliative and Supportive Care Group.

Publication status and date: New, published in Issue 5, 2016.

Citation: Cooper TE, Hambleton IR, Ballas SK, Wiffen PJ. Pharmacological interventions for painful sickle cell vaso-occlusive crises in adults. Cochrane Database of Systematic Reviews 2016, Issue 5. Art. No.: CD012187. DOI: 10.1002/14651858.CD012187.

Copyright (C) 2016 The Cochrane Collaboration. Published by John Wiley \& Sons, Ltd.

\begin{abstract}
A B S T R A C T
This is the protocol for a review and there is no abstract. The objectives are as follows:

To assess the analgesic efficacy, and adverse events, of pharmacological interventions used to treat acute painful sickle cell vaso-occlusive crises in adults, aged 18 and over, in any setting.
\end{abstract}

\section{B A C K G R O U N D}

A previous review, titled 'Pain management for sickle cell disease in children and adults' was withdrawn as it was out of date ( Dunlop 2014). This is a completely new review focusing only on the painful vaso-occlusive crises (or episodes) of sickle cell disease and it excludes the paediatric population.

\section{Description of the condition}

Sickle cell disease is a generic term for a group of inherited disorders of haemoglobin $(\mathrm{Hb})$ structure in which the affected person inherits two mutant globin genes (one from each parent), at least one of which is always the sickle mutation (WHO 2010). The latter results from a single nucleotide change (GAT $\rightarrow$ GTT) in the sixth codon of exon 1 of the $\beta$-globin gene responsible for the synthesis of the $\beta$-globin chain. The resulting replacement of the normal glutamic acid by valine at position 6 in the $\beta$ chain leads to the formation of sickle $\mathrm{Hb}(\mathrm{Hb} \mathrm{S})$. Sickle cell anaemia is the homozygous state, in which the sickle gene is inherited from both parents. Other sickle cell syndromes result from the co-inheritance of the sickle gene and a non-sickle gene, such as in $\mathrm{Hb} \mathrm{C}, \mathrm{Hb}$ OArab, Hb D, $\beta$ +-thalassaemia, or $\beta 0$-thalassemia (NIH 2014). The abnormally shaped red blood cell was first described by JB Herrick in 1910 (Herrick 1910). Sickle cell originated in Sub-Saharan Africa and the Indian subcontinent (Stuart 2004; Weatherall 2006; Martí-Carvajal 2009), but has persisted as a recessive trait due to the survival advantage against malaria enjoyed by people with the heterozygote form (Weatherall 2001). If location were the key determinant, people of African, Mediterranean, Middle Eastern, Indian and Latin-American descent would be perceived at highest risk (Sasongko 2013). However, in recent years, the United Nations and the World Health Organisation have recog- 
nised sickle cell disease as a global public health problem (WHO 2010) due to population mobility, with increased migration from high-to low-frequency sickle haemoglobin areas. Combined with the global increase in population size, reduction in child mortality and improved adult survival, the worldwide burden of sickle cell disease is predicted to increase during the next several decades ( $\mathrm{Al}$ Hajeri 2007; Martí-Carvajal 2009; Piel 2013).

Epidemiologically, it is estimated that somewhere between 5\% (approximately 367 million people) (WHO 2011) and 7\% (approximately 500 million people) (Weatherall 2001) of the world's population are carriers of the mutant haemoglobin gene. The prevalence of sickle cell disease in a given population is determined by the prevalence of the sickle cell trait. If the prevalence of the trait is around $25 \%$ in a given population, then the prevalence of the disease at birth can be estimated to be approximately $2 \%$ (Cook 2003; WHO 2010).

Sickle cell disease is the most common inherited blood disorder globally. Worldwide, the African region has the highest prevalence with approximately 200,000 babies born with sickle cell disease every year (Diallo 2002; Martí-Carvajal 2009). In 2010, approximately $75 \%$ of the globally estimated homozygous sickle cell disease newborns were from Sub-Saharan Africa (Piel 2013). In the United States, the prevalence of sickle cell disease is approximately 100,000 and it predominantly affects Americans of African descent (NIH 2015). In addition to this, 3.5 million African-Americans have the sickle cell trait $\mathrm{HbAS}$ genotype (i.e. are heterozygote carriers of sickle haemoglobin) (Yawn 2014). The United Kingdom reports a prevalence of approximately 12,500 people with the disease (National Screening Committee 2006).

Shortened lifespans are attributable to serious co-morbidities associated with the disease, including renal failure, pulmonary hypertension, pulmonary embolus, stroke, acute chest syndrome and sepsis (Tanabe 2012). For example, African-Americans with sickle cell disease have a life expectancy of 48 for females and 42 for males, compared with the life expectancy of African-Americans without sickle cell disease of 77 and 71 (respectively) (Platt 1994; Tanabe 2012). However, there is uncertainty in these estimates as different countries report longer median survival rates. For example, the median survival rate of the Jamaican sub-population is 58.5 years for females and 53 for males (Wierenga 2001).

Sickle cell disease is characterised by the presence of distorted sickle-shaped red blood cells in the blood stream. These sickleshaped cells arise as a result of the "polymerisation (gelling of the molecules) of the abnormal haemoglobin in the red blood cells when they release their combined oxygen" (Al Hajeri 2007). Many manifestations of the disease are attributed to either haemolysis (premature red cell destruction) or vaso-occlusion (obstruction of blood flow), which is the most common manifestation (Al Hajeri 2007). Red cell dehydration contributes to vaso-occlusion: dehydrated red cells adhere to vascular endothelium, which results in blockage of blood flow (Lutz 2015). Other severe outcomes of the manifestations of sickle cell disease can include acute chest syndrome (chest crisis), priapism, acute cholecystitis, acute stroke and aplastic crisis (NIH 2014).

Vaso-occlusion can lead to acute, painful crisis. This is also known as a sickle cell crisis, vaso-occlusive crisis or vaso-occlusive episode. Pain is most often reported in the joints, extremities, back or chest, but it can occur anywhere and can last for several days or weeks. The frequency and severity of the painful episodes vary widely within and between individuals. The peak incidence is in late adolescence and early adulthood (Ballas 2007). The bone and muscle pain experienced during a sickle cell crisis is both acute (sudden onset of severe intensity) and recurrent (reoccurring unpredictably and intermittently over long periods of time whilst fluctuating in frequency and quality) (Serjeant 1994; Thienhaus 2002).

This review will focus on the vaso-occlusive manifestation of the disease, which causes the acute and painful crises (episodes). It will exclude the other possible outcomes in sickle cell disease patients.

\section{Description of the intervention}

A vaso-occlusive crisis can require several interventions, depending on the patient and situation. Treatment for vaso-occlusive crisis is primarily symptomatic and aims to stabilise pain. As well as pharmacological agents, non-pharmacological approaches, such as relaxation, hypnosis, heat, ice and acupuncture, have been used to rehydrate the patient and reduce the sickling process (Ballas 2005; Ballas 2007; De Ceulaer 1982; Gaston 1986; Lane 2001; Okomo 2015).

In this review, we will assess pharmacological interventions used to treat vaso-occlusive crises in adults living with sickle cell disease. These include (but are not limited to) analgesic opioids, nonanalgesic opioids, partial agonists, mixed agonists-antagonists, antagonists and adjuvants (Ballas 2007).

In context, a vaso-occlusive crisis is the hallmark of sickle cell disease and is the most common cause of hospitalisation in patients (up to 90\%) (Ballas 2005; Dampier 2013). Therefore, treatment for adults with vaso-occlusive crisis is usually on presentation to an emergency healthcare facility, where the patient should (in industrialised countries) receive treatment if they report 30 minutes or more of acute and debilitating pain (Lanzkron 2015). In addition, some sickle cell disease patients often self medicate at home with pharmacological agents. In both settings, primary management should be focused on rapid pain control, whereby fluids and analgesics should be administered immediately (NICE 2015). Vaso-occlusive crisis can be treated with various drugs (described below). As with all pharmacotherapies, the risk of adverse effects can be minimised by prescribing the lowest dose for the shortest duration possible to control the symptoms (NICE 2015).

For all analgesia, the patient's respiratory rate, pain and sedation are assessed at 20-minute intervals until pain control is reached, then monitored with analgesia re-administered every four hours (NICE 2015; Rees 2003). Patient-controlled administration (PCA) is also 
an option and commonly used in adolescents transitioning into adult care (Telfer 2014).

A. Opioid analgesics are recommended as the primary choice of pain relief in vaso-occlusive crisis management (NICE 2015). They include (but are not limited to): codeine, hydrocodone/paracetamol (acetaminophen), hydrocodone/ibuprofen, oxycodone (and with codeine), morphine, hydromorphone, oxymorphone, methadone, diamorphine and fentanyl (Ballas 2007). Opioids are generally available in healthcare settings in most Western countries and are often delivered as intravenous morphine every four to six hours. In addition, oral opioids are also prescribed as patient-administered analgesia after a vaso-occlusive crisis episode (NICE 2015).

Most analgesic opioids have a half-life of two to four hours, with the exception of methadone, propoxyphene and meperidine, for which this can be one to several days (Trescot 2008). Although the standard dosing is generally every four to six hours, some patients develop tolerance to opioids, thus requiring doses every two hours (Okpala 2002). Combination with diclofenac or paracetamol (which have different mechanisms of action) will help to keep opioid use to a minimum (Okpala 2002).

The adverse effects of analgesic opioids include: (short-term) respiratory depression, constipation, vomiting, nausea, pruritus and hives (Ballas 2007), addiction and withdrawals (Rosenblum 2008).

B. Non-opioid analgesics are the other drugs of choice for managing a vaso-occlusive crisis (NICE 2015). These include: acetaminophen (paracetamol), non-selective COX inhibitors (acetylsalicylic acid, ibuprofen, naproxen, ketorolac) and selective COX-2 inhibitors (celecoxib) (Ballas 2007).

The most commonly used drugs from this family are non-steroidal anti-inflammatory drugs (NSAIDs), paracetamol, diclofenac and ketorolac. They are commonly used for mild to moderate pain either alone or in combination with opioid analgesia (Rees 2003). NSAIDs are available in most countries. The adverse effects of NSAIDs include gastrointestinal complications and they should be administered with caution in patients with a history of renal failure, bleeding tendencies, asthma or peptic ulcer (Rees 2003). Paracetamol is also widely available in Western countries and is administered orally at a dosage of $200 \mathrm{mg}$ to $500 \mathrm{mg}$ every four to six hours until satisfactory pain relief has been achieved. The adverse effects of paracetamol are influenced by the dosage and duration of use and can include liver failure (Rees 2003).

C. Other pharmacotherapeutic drugs to be considered for analysis in this review include partial agonists (examples include buprenorphine and buprenorphine/naloxone), mixed agonist-antagonists (examples include pentazocine, nalbuphine and butorphanol) and hydroxyurea (Ballas 2007). Finally, we will also consider any other pharmacotherapeutic drugs that we find, which are used to treat vaso-occlusive crisis.

\section{How the intervention might work}

Analgesics work in a number of different ways to treat vaso-occlusive crisis, thus the key factor is whether the drugs provide relief of participant-reported pain. Therefore, we are interested in gathering a comprehensive list of all pharmacotherapeutic treatments that have been trialled in a clinical setting to treat an episode (new or recurrent) in diagnosed sickle cell disease patients. We are also interested in combination drug therapies.

\section{Why it is important to do this review}

Globally, sickle cell disease is one of the four most common autosomal recessive disorders, along with thalassaemia, Tay-Sachs disease and cystic fibrosis (Hussein 2015). In addition, in many industrialised countries there has been an improvement in the survival rate of children with sickle cell disease who now live on into adulthood (approximately 98.4\%), thus increasing the adult population living with this condition (Quinn 2010; Sasongko 2013). We are unaware of any recent or up-to-date systematic reviews that draw on comparisons of a full range of pharmacotherapies used specifically to treat vaso-occlusive crisis in adults. Therefore, this review will aim to address and analyse all available pharmacotherapies, including drug combinations.

This systematic review will also address the issue of tolerance or habituation to opioids where this is reported in sickle cell disease patients (Tanabe 2012; Waldrop 1995). Regular analgesia should be given for acute pain when presenting in the emergency setting. Due to patients developing a tolerance and requiring more frequent doses, it has been suggested that every effort should be made to prevent such tolerance developing in new patients because there is a limited choice of injectable opioids that can be used in acute painful episodes (Okpala 2002). In recent qualitative surveys of health professionals, there is a common view, despite a lack of evidence, that compared to all emergency department patients presenting with pain a higher frequency of sickle cell disease patients are addicted to opioids and that they are usually seeking out drugs for this dependency (Tanabe 2012; Waldrop 1995). Continuity of care can be lacking for people with sickle cell disease, reiterating the fact that up-to-date clinical guidance for health professionals in primary care and emergency care is critically needed (Yawn 2014). Therefore it is important to conduct this review to investigate combination analgesics that have different mechanisms of action, in order to keep opioid doses to a minimum (Okpala 2002). A systematic review of the current evidence on the reported benefits and harms is required to clarify the most effective pharmacotherapeutic options (and combinations) for effective pain relief interventions in adult patients with acute painful sickle cell vasoocclusive crises.

\section{O B JE C T IVES}

Pharmacological interventions for painful sickle cell vaso-occlusive crises in adults (Protocol) 
To assess the analgesic efficacy, and adverse events, of pharmacological interventions used to treat acute painful sickle cell vasoocclusive crises in adults, aged 18 and over, in any setting.

\section{METHODS}

\section{Criteria for considering studies for this review}

\section{Types of studies}

We will include randomised controlled trials (RCTs) with double-blind assessment of participant outcomes following immediate treatment for acute painful sickle cell vaso-occlusive episodes. We will also consider cross-over studies. We require full journal publication, with the exception of online clinical trial results, summaries of otherwise unpublished clinical trials and extended abstracts of otherwise unpublished clinical trials if sufficient data can be analysed. We will exclude studies that are non-randomised, studies of experimental pain, case reports and clinical observations.

\section{Types of participants}

Studies will include adult participants, aged 18 years and above, who are diagnosed with sickle cell disease and who have an acute painful sickle cell vaso-occlusive crisis (new or recurring).

We will consider including studies that contain some participants below 18 years (such as adolescent participants mixed with adult participants over 18 years). In this case we will extract the data on participants aged 18 years and above. We will contact the authors of trials for the separate adult data if necessary.

\section{Types of interventions}

Any pharmacological intervention at any dose, by any route, administered for the relief of acute pain associated with a sickle cell vaso-occlusive episode or event (new or recurring) and compared to placebo or any active comparator.

We will include studies treating the crisis in any health setting, as well as combination drug regimes. Intravenous fluid replacement therapy is a primary step in the NICE guidelines for managing a sickle cell crisis (NICE 2015) and is therefore considered standard practice and not an active comparator for the purpose of this review. We will not include studies using agents to treat pain resulting from other causes. We will not include studies using agents to attempt to treat the cause of sickle cell disease, chronic pain or non-painful symptoms of the disease.

\section{Types of outcome measures}

Studies must report pain assessment as either a primary or secondary outcome to be eligible for this review.

We anticipate that studies will use a variety of outcome measures, with the majority of studies using standard subjective scales (numerical rating scale (NRS) or visual analogue scale (VAS)) for pain intensity or pain relief, or both (Dworkin 2008).

We will use the following dichotomous measures of pain: at least $50 \%$ pain relief over baseline (substantial), at least 30\% pain relief over baseline (moderate), very much improved on the Patient Global Impression of Change (PGIC) (substantial), and much or very much improved on the PGIC (moderate). These outcomes are different from those used in most earlier reviews (Wiffen 2005), and we recognise that continuous responses to chronic pain generally do not follow a normal (Gaussian) distribution. People with chronic pain desire high levels of pain relief, ideally more than $50 \%$ and ideally leading to no more than mild pain (Moore 2013a; O'Brien 2010). For the purpose of this review, we consider it appropriate to adapt these measurements of chronic pain to acute painful episodes.

We will include a 'Summary of findings' table as set out in the author guide ( $\mathrm{PaPaS}$ 2012). The 'Summary of findings' table will include outcomes of at least $30 \%$ and at least $50 \%$ pain intensity reduction, PGIC, withdrawals due to adverse events, serious adverse events and death. We will use the GRADE approach to assess the quality of the evidence related to each of the key outcomes listed in here (Chapter 12, Higgins 2011), as appropriate.

\section{Primary outcomes}

- Participant-reported pain relief of $50 \%$ or greater at 6,12 , 24, 48 hours and at the end of treatment.

- Participant-reported pain relief of $30 \%$ or greater at 6,12 , 24, 48 hours and at the end of treatment.

- Patient global impression of change (PGIC) very much improved.

- Patient global impression of change (PGIC) much or very much improved.

\section{Secondary outcomes}

- Opioid consumption.

- Time to pain resolution.

- Length of hospitalisation.

- Participants experiencing any adverse or serious adverse event. Serious adverse events typically include any untoward medical occurrence or effect that at any dose results in death, is life-threatening, requires hospitalisation or prolongation of existing hospitalisation, results in persistent or significant disability or incapacity, is a congenital anomaly or birth defect, is an 'important medical event' that may jeopardise the patient, or may require an intervention to prevent one of the above 
characteristics or consequences. Acute chest syndrome is well documented as a reported adverse event of vaso-occlusive crisis and we will assess the issues around tolerability of the drugs.

- Any pain-related outcome indicating some improvement, such as sleep quality or activities of daily living.

- Withdrawals due to lack of efficacy, adverse events and for any cause.

- Reports of tolerance or habituation to opioids.

These secondary outcomes are not eligibility criteria for this review, but are outcomes of interest within whichever studies are included.

\section{Search methods for identification of studies}

The Information Specialist will carry out the searches.

\section{Electronic searches}

We will search the following databases without language restrictions:

- Cochrane Central Register of Controlled Trials

(CENTRAL) (via The Cochrane Library);

- MEDLINE (via Ovid);

- EMBASE (via Ovid);

- LILACS.

We will use medical subject headings $(\mathrm{MeSH})$ or equivalent and text-word terms. We will tailor the searches to the individual databases.

The search strategy for MEDLINE is in Appendix 1.

\section{Searching other resources}

We will search the metaRegister of controlled trials ( $m$ RCT) (http:/ /www.isrctn.com/), ClinicalTrials.gov (www.clinicaltrials.gov) and the World Health Organisation (WHO) International Clinical Trials Registry Platform (ICTRP) (http://apps.who.int/ trialsearch/) for ongoing trials. In addition,we will check the reference lists of reviews and retrieved articles for additional studies and perform citation searches on key articles.

\section{Data collection and analysis}

\section{Selection of studies}

Two review authors (TC and SB) will independently determine eligibility by reading the title and abstract of each study identified by the search. The independent review authors will eliminate studies that clearly do not satisfy the inclusion criteria and obtain full copies of the remaining studies.

Two review authors (TC and SB) will read these reports independently to select relevant studies. In the event of disagreement, a third author will adjudicate (PW). We will not anonymise the studies in any way before assessment. We will include a Preferred Reporting Items for Systematic Reviews and Meta-Analyses (PRISMA) flow chart in the full review, which will show the status of identified studies (Moher 2009), as recommended in Part 2, Section 11.2.1 of the Cochrane Handbook for Systematic Reviews of Interventions (Higgins 2011). We will include studies in the review irrespective of whether measured outcome data are reported in a 'usable' way.

\section{Data extraction and management}

Two review authors (TC and $\mathrm{IH}$ ) will independently extract data using a standard form and check for agreement before entry into Review Manager (RevMan 2014).

We will include information about the pain condition, number of participants treated, drug and dosing regimen, study design (placebo or active control), study duration and follow-up, analgesic outcome measures and results, withdrawals and adverse events (participants experiencing any adverse event or serious adverse event).

We will collate multiple reports of the same study, so that each study rather than each report is the unit of interest in the review. We will collect characteristics of the included studies in sufficient detail to populate a table of 'Characteristics of included studies' in the full review.

\section{Assessment of risk of bias in included studies}

Two authors (TC and SB) will independently assess risk of bias for each study, using the criteria outlined in the Cochrane Handbook for Systematic Reviews of Interventions (Higgins 2011), adapted from those used by the Cochrane Pregnancy and Childbirth Group, with any disagreements resolved by discussion. We will complete a 'Risk of bias' table for each included study using the 'Risk of bias' tool in Review Manager (RevMan) (RevMan 2014).

We will assess the following for each study.

- Random sequence generation (checking for possible selection bias). We will assess the method used to generate the allocation sequence as: low risk of bias (any truly random process, e.g. random number table; computer random number generator); unclear risk of bias (method used to generate sequence not clearly stated). We will exclude studies using a nonrandom process (e.g. odd or even date of birth; hospital or clinic record number).

- Allocation concealment (checking for possible selection bias). The method used to conceal allocation to interventions prior to assignment determines whether intervention allocation could have been foreseen in advance of, or during, recruitment or changed after assignment. We will assess the methods as: low risk of bias (e.g. telephone or central randomisation; consecutively numbered, sealed, opaque envelopes); unclear risk 
of bias (method not clearly stated). We will exclude studies that do not conceal allocation (e.g. open list).

- Blinding of outcome assessment (checking for possible detection bias). We will assess the methods used to blind study participants and outcome assessors from knowledge of which intervention a participant received. We will assess the methods as: low risk of bias (study states that it was blinded and describes the method used to achieve blinding, e.g. identical tablets; matched in appearance and smell); unclear risk of bias (study states that it was blinded but does not provide an adequate description of how it was achieved). We will exclude studies that were not double-blind.

- Incomplete outcome data (checking for possible attrition bias due to the amount, nature and handling of incomplete outcome data). We will assess the methods used to deal with incomplete data as: low risk (less than $10 \%$ of participants did not complete the study or used 'baseline observation carried forward' analysis, or both); unclear risk of bias (used 'last observation carried forward' analysis); high risk of bias (used 'completer' analysis).

- Size of study (checking for possible biases confounded by small size). We will assess studies as being at low risk of bias (200 participants or more per treatment arm); unclear risk of bias (50 to 199 participants per treatment arm); high risk of bias (fewer than 50 participants per treatment arm).

\section{Measures of treatment effect}

We will use dichotomous data to calculate risk ratios (RR) with 95\% confidence intervals (CI) using a fixed-effect model unless significant statistical heterogeneity is found (see below).

We will calculate NNTs as the reciprocal of the absolute risk reduction (ARR; McQuay 1998). For unwanted effects, the NNT becomes the number needed to treat to harm $(\mathrm{NNH})$ and is calculated in the same manner. Where the unwanted effect is less common with treatment than control, we will use the term number needed to treat to prevent (NNTp).

We will not use continuous data in analyses because it is inappropriate where there is underlying skewed distribution, as is usually the case with analgesic response.

\section{Unit of analysis issues}

We expect that for all included studies, the unit of analysis will be at the participant level, with each participant providing one pain episode per trial. It is possible, though unlikely, that a trial may include multiple pain events per participant, introducing a clustering effect. In this scenario we will use the number of trial clusters and an estimate of the intra class correlation coefficient to inflate the standard errors associated with each clustered trial.

\section{Assessment of heterogeneity}

When possible, we will deal with clinical heterogeneity (variation in participants, interventions or outcomes) by combining studies that examine similar conditions. We will assess statistical heterogeneity visually (L'Abbé 1987), and with the use of the $\mathrm{I}^{2}$ statistic. When the $\mathrm{I}^{2}$ value is greater than $50 \%$, we will consider the possible reasons for this.

\section{Assessment of reporting biases}

The aim of this review is to use dichotomous outcomes of known utility and of value to patients (Hoffman 2010; Moore 2010b; Moore 2010c; Moore 2010d; Moore 2013a). The review will not depend on what the authors of the original studies chose to report or not, though clearly difficulties will arise in studies failing to report any dichotomous results. We will extract and use continuous data, which will probably poorly reflect efficacy and utility and may be useful for illustrative purposes only.

We will assess publication bias using a method designed to detect the amount of unpublished data with a null effect required to make any result clinically irrelevant (usually taken to mean a NNT of 10 or higher; Moore 2008).

\section{Data synthesis}

We plan to use a fixed-effect model for meta-analysis. We will use a random-effects model for meta-analysis if there is significant clinical heterogeneity and it is considered appropriate to combine studies. We will use the Cochrane software program Review Manager (RevMan 2014).

Two review authors (TC, SB) will independently rate the quality of the evidence for each outcome. We will use the GRADE (Grades of Recommendation, Assessment, Development and Evaluation) system to rank the quality of the evidence using the GRADEprofiler Guideline Development Tool software (GRADEpro GDT 2015), and the guidelines provided in Chapter 12.2 of the Cochrane Handbook for Systematic Reviews of Interventions (Higgins 2011).

The GRADE approach uses five considerations (study limitations, consistency of effect, imprecision, indirectness and publication bias) to assess the quality of the body of evidence for each outcome. The GRADE system uses the following criteria for assigning the grade of evidence:

- High: further research is very unlikely to change our confidence in the estimate of effect;

- Moderate: further research is likely to have an important impact on our confidence in the estimate of effect and may change the estimate;

- Low: further research is very likely to have an important impact on our confidence in the estimate of effect and is likely to change the estimate;

- Very low: any estimate of effect is very uncertain.

We will decrease the grade due to: 
- serious (-1) or very serious (-2) limitation to study quality;

- important inconsistency $(-1)$;

- some (-1) or major (-2) uncertainty about directness;

- imprecise or sparse data $(-1)$;

- high probability of reporting bias (-1).

\section{Subgroup analysis and investigation of heterogeneity}

We do not plan any subgroup analyses since experience from previous reviews suggests a limited chance of sufficient data. However, we will consider subgroup classification between genotypes should the data be available.

\section{Sensitivity analysis}

We plan no sensitivity analysis because the evidence base is known to be too small to allow reliable analysis. We will not pool results from sickle cell pain pain of different origins in the primary analyses. We will examine details of dose escalation schedules in the unlikely situation that this could provide some basis for a sensitivity analysis.

\section{ACKNOWLEDGEMENTS}

Institutional support is provided by the Oxford Pain Relief Trust.

The National Institute for Health Research (NIHR) is the largest single funder of the Cochrane PaPaS Group. Disclaimer: The views and opinions expressed therein are those of the authors and do not necessarily reflect those of the NIHR, National Health Service (NHS) or the Department of Health.

The review was carried out in conjunction with the Cochrane Cystic Fibrosis and Genetic Disorders Group.

\section{R E F E R E N C E S}

\section{Additional references}

\section{Al Hajeri 2007}

Al Hajeri A, Fedorowicz Z, Omran A, Tadmouri GO. Piracetam for reducing the incidence of painful sickle cell disease crises. Cochrane Database of Systematic Reviews 2007, Issue 2. [DOI: 10.1002/14651858.CD006111.pub2]

Ballas 2005

Ballas SK. Pain management of sickle cell disease. Hematology/Oncology Clinics of North America 2005;19(5): 785-802. [DOI: 10.1016/j.hoc.2005.07.008]

Ballas 2007

Ballas SK. Current issues in sickle cell pain and its management. Hematology 2007;2007(1):97-105. [DOI: 10.1182/asheducation-2007.1.97]

\section{Cook 2003}

Cook GC, Zumla AI (editors). Manson's Tropical Diseases. 21st Edition. London: WB Saunders, 2003.

\section{Dampier 2013}

Dampier CD, Smith WR, Wager CG, Kim HY, Bell MC, Miller ST, et al. IMPROVE trial: A randomized controlled trial of patient-controlled analgesia for sickle cell painful episodes: rationale, design challenges, initial experience and recommendations for future studies. Clinical Trials 2013; 10(2):319-31. [DOI: 10.1177/1740774513475850]

\section{De Ceulaer 1982}

De Ceulaer K, Hayes R, Gruber C, Serjeant GR. Medroxyprogesterone acetate and homozygous sickle-cell disease. Lancet 1982;2(8292):229-31. [DOI: 10.1016/ S0140-6736(82)90320-8]
Diallo 2002

Diallo D, Tchernia G. Sickle cell disease in Africa. Current Opinion in Hematology 2002;9(2):111-6. [ISSN: 1065-6251]

\section{Dunlop 2014}

Dunlop R, Bennet KCLB. Pain management for sickle cell disease in children and adults. Cochrane Database of Systematic Reviews 2014, Issue 4. [DOI: 10.1002/ 14651858.CD003350.pub3]

\section{Dworkin 2008}

Dworkin RH, Turk DC, Wyrwich KW, Beaton D, Cleeland $\mathrm{CS}$, Farrar JT, et al. Interpreting the clinical importance of treatment outcomes in chronic pain clinical trials: IMMPACT recommendations. Journal of Pain 2008;9(2): 105-21. [DOI: 10.1016/j.jpain.2007.09.005]

\section{Gaston 1986}

Gaston MH, Verter JI, Woods G, Pegelow C, Kelleher J, Presbury G, et al. Prophylaxis with oral penicillin in children with sickle cell anemia. A randomized trial. New England Journal of Medicine 1986;314(25):1593-9. [DOI: 10.1056/NEJM198606193142501]

\section{GRADEpro GDT 2015 [Computer program]} McMaster University (developed by Evidence Prime, Inc.). GRADEpro Guideline Development Tool. McMaster University (developed by Evidence Prime, Inc.), 2015.

\section{Herrick 1910}

Herrick J. Peculiar elongated and sickle-shaped red blood corpuscles in a case of severe anemia. Archives or Internal Medicine 1910;5(5):517-21. [DOI: 10.1001-archinte.1910.00050330050003] 


\section{Higgins 2011}

Higgins JPT, Altman DG, Sterne JAC (editors). Chapter 8: Assessing risk of bias in included studies. In: Higgins JPT, Green S (editors). Cochrane Handbook for Systematic Reviews of Interventions Version 5.1.0 [updated March 2011]. The Cochrane Collaboration, 2011. Available from www.cochrane-handbook.org.

Hoffman 2010

Hoffman DL, Sadosky A, Dukes EM, Alvir J. How do changes in pain severity levels correspond to changes in health status and function in patients with painful diabetic peripheral neuropathy?. Pain 2010;149(2):194-201. [DOI: 10.1016/j.pain.2009.09.017]

\section{Hussein 2015}

Hussein N, Weng SF, Kai J, Kleijnen J, Quershi N. Preconception risk assessment for thalassaemia, sickle cell disease, cystic fibrosis and Tay-Sachs disease. Cochrane Database of Systematic Reviews 2015, Issue 8. [DOI: 10.1002/14651858.CD010849.pub2]

L'Abbé 1987

L'Abbé KA, Detsky AS, O'Rourke K. Meta-analysis in clinical research. Annals of Internal Medicine 1987;107(2): 224-33. [DOI: 10.7326/0003-4819-107-2-224]

\section{Lane 2001}

Lane PA, Nuss R, Ambruso D. Hematologic disorders. In: Hay WW, Hayward AR, Levin MJ, Sondheimer JM editor(s). Current Pediatric Diagnosis and Treatment. 15th Edition. New York: McGraw-Hill Companies Inc., 2001: 756-9.

\section{Lanzkron 2015}

Lanzkron S, Carroll CP, Hill P, David M, Paul N, Haywood Jr C. Impact of a dedicated infusion clinic for acute management of adults with sickle cell pain crisis. American Journal of Hematology 2015;90(5):376-80. [DOI: 10.1002/ ajh.23961]

Lutz 2015

Lutz B, Meiler SE, Bekker A, Tao Y-X. Updated Mechanisms of Sickle Cell Disease-Associated Chronic Pain. Translational Perioperative and Pain Medicine 2015;2 (2):8-17. [PUBMED: PMC4542088]

\section{Martí-Carvajal 2009}

Martí-Carvajal AJ, Peña-Martí GE, Comunián-Carrasco G, Martí-Peña AJ. Interventions for treating painful sickle cell crisis during pregnancy. Cochrane Database of Systematic Reviews 2009, Issue 1. [DOI: 10.1002/ 14651858.CD006786.pub2]

\section{McQuay 1998}

McQuay H, Moore R. An Evidence-based Resource for Pain Relief. Oxford: Oxford University Press, 1998. [ISBN: 0-19-263048-2]

\section{Moher 2009}

Moher D, Liberati A, Tetzlaff J, Altman DG, the PRISMA Group. Preferred Reporting Items for Systematic Reviews and Meta-analyses: The PRISMA Statement. PLoS Medicine 2009;6(7):e1000097.

\section{Moore 2008}

Moore RA, Barden J, Derry S, McQuay HJ. Managing potential publication bias. In: McQuay HJ, Kalso E, Moore RA editor(s). Systematic Reviews in Pain Research: Methodology Refined. Seattle: IASP Press, 2008:15-24. [ISBN: 978-0-931092-69-5]

\section{Moore 2010b}

Moore RA, Straube S, Paine J, Phillips CJ, Derry S, McQuay HJ. Fibromyalgia: moderate and substantial pain intensity reduction predicts improvement in other outcomes and substantial quality of life gain. Pain 2010;149(2):360-4. [DOI: 10.1016/j.pain.2010.02.039]

\section{Moore 2010c}

Moore RA, Moore OA, Derry S, Peloso PM, Gammaitoni AR, Wang H. Responder analysis for pain relief and numbers needed to treat in a meta-analysis of etoricoxib osteoarthritis trials: bridging a gap between clinical trials and clinical practice. Annals of the Rheumatic Diseases 2010; 69(2):374-9. [DOI: 10.1136/ard.2009.107805]

\section{Moore 2010d}

Moore RA, Smugar SS, Wang H, Peloso PM, Gammaitoni A. Numbers-needed-to-treat analyses - do timing, dropouts, and outcome matter? Pooled analysis of two randomized, placebo-controlled chronic low back pain trials. Pain 2010; 151(3):592-7. [DOI: 10.1016/j.pain.2010.07.013]

\section{Moore 2013a}

Moore RA, Straube S, Aldington D. Pain measures and cut-offs - 'no worse than mild pain' as a simple, universal outcome. Anaesthesia 2013;68(4):400-12. [DOI: 10.1111/ anae. 12148]

National Screening Committee 2006 National Screening Committee for Sickle Cell Disease and Thalassaemia. NHS Sickle Cell and Thalassaemia Screening Programme. https://www.gov.uk/topic/populationscreening-programmes/sickle-cell-thalassaemia (accessed 7 September 2015) 2006.

\section{NICE 2015}

National Institute of Health and Care Excellence (NICE). Guidance - Sickle Cell Acute Painful Episode. http:// www.nice.org.uk/ (accessed 7 September 2015) 2015.

\section{NIH 2014}

National Institutes of Health. Evidence-Based Management of Sickle Cell Disease: Expert Panel Report. http:// www.nhlbi.nih.gov/guidelines 2014.

\section{NIH 2015}

National Heart, Lung and Blood Institute. Sickle Cell Disease. National Institutes of Health http:// www.nhlbi.nih.gov/health/health-topics/topics/sca/atrisk (accessed 12 October 2015) 2015.

\section{O'Brien 2010}

O'Brien EM, Staud RM, Hassinger AD, McCulloch RC, Craggs JG, Atchison JW, et al. Patient-centered perspective on treatment outcomes in chronic pain. Pain Medicine 2010; 11(1):6-15. [DOI: 10.1111/j.1526-4637.2009.00685.x] 


\section{Okomo 2015}

Okomo U, Meremikwu MM. Fluid replacement therapy for acute episodes of pain in people with sickle cell disease. Cochrane Database of Systematic Reviews 2015, Issue 3. [DOI: 10.1002/14651858.CD005406.pub4]

\section{Okpala 2002}

Okpala I, Tawil A. Management of pain in sickle-cell disease. Journal of the Royal Society of Medicine 2002;95(9): 456-8. [PUBMED: PMC1279994]

\section{PaPaS 2012}

$\mathrm{PaPaS}$ author and referee guidance. http:// papas.cochrane.org/papas-documents (accessed 17 August 2015).

\section{Piel 2013}

Piel FB, Patil AP, Howes RE, Nyangiri OA, Gething PW, Dewi $\mathrm{M}$, et al. Global epidemiology of sickle haemoglobin in neonates: a contemporary geostatistical model-based map and population estimates. Lancet 2013;381(9861): 142-51. [DOI: 10.1016/S0140-6736(12)61229-X]

\section{Platt 1994}

Platt OS, Brambilla DJ, Rosse WF, Milner PF, Castro O, Steinberg MH, et al. Mortality in sickle cell disease: life expectancy and risk factors for early death. New England Journal of Medicine 1994;330(23):1639-44. [DOI: 10.1056/NEJM199406093302303]

\section{Quinn 2010}

Quinn CT, Rogers ZR, McCavit TL, Buchanan GR. Improved survival of children and adolescents with sickle cell disease. Blood 2010;115(17):3447-52. [DOI: 10.1182/ blood-2009-07-233700]

Rees 2003

Rees DC, Olujohungbe AD, Parker NE, Stephens AD, Telfer P, Wright J. Guidelines for the management of the acute painful crisis in sickle cell disease. British Journal of Haematology 2003;120(5):744. [DOI: 10.1046/ j.1365-2141.2003.04193]

\section{RevMan 2014 [Computer program]}

The Nordic Cochrane Centre, The Cochrane Collaboration. Review Manager (RevMan). Version 5.3. Copenhagen: The Nordic Cochrane Centre, The Cochrane Collaboration, 2014.

\section{Rosenblum 2008}

Rosenblum A, Marsch LA, Joseph H, Portenoy RK. Opioids and the treatment of chronic pain: controversies, current status, and future directions. Experimental and Clinical Psychopharmacology 2008;16(5):405-16. [DOI: $10.1037 /$ a0013628]

\section{Sasongko 2013}

Sasongko TH, Nagalla S, Ballas SK. Angiotensinconverting enzyme (ACE) inhibitors for proteinuria and microalbuminuria in people with sickle cell disease. Cochrane Database of Systematic Reviews 2013, Issue 3. [DOI: 10.1002/14651858.CD009191.pub2]

\section{Serjeant 1994}

Serjeant GR. The geography of sickle-cell disease: opportunity for understanding its diversity. Annals of Saudi Medicine 1994;14(3):237-46. [PUBMED: 17586900]

\section{Stuart 2004}

Stuart MJ, Nagel RL. Sickle-cell disease. Lancet 2004; 364(9442):1343-60. [DOI: 10.1016/S0140-6736 (04) 17192-4]

\section{Tanabe 2012}

Tanabe P, Hafner J, Martinovich Z, Artz N. Adult emergency department patients with sickle cell pain crisis: results from a quality improvement learning collaborative model to improve analgesic management. Academic Emergency Medicine 2012;9(4):430-8. [DOI: 10.1111/ j.1553-2712.2012.01330.x]

\section{Telfer 2014}

Telfer P, Bahal N, Lo A, Challands J. Management of the acute painful crisis in sickle cell disease - a re-evaluation of the use of opioids in adult patients. British Journal of Haematology 2014;166:157-64. [DOI: 10.1111/ bjh.12879]

\section{Thienhaus 2002}

Thienhaus O, Cole BE. Classification of pain. In: Weiner RS editor(s). Pain management: a practical guide for clinicians. 6th Edition. New York, NY: CRC Press, 2002.

\section{Trescot 2008}

Trescot M, Datta S, Lee M, Hansen H. Opioid pharmacology. Pain Physician Journal 2008;11(2S): S133-53. [ISSN: 1533-3159; PUBMED: 18443637]

\section{Waldrop 1995}

Waldrop RD, Mandry C. Health professional perceptions of opioid depended among patients with pain. American Journal of Emergency Medicine 1995;13(5):529-31. [DOI: 10.1016/0735-6757(95)90163-9]

\section{Weatherall 2001}

Weatherall DJ, Clegg JB. Inherited haemoglobin disorders: an increasing global health problem. Bulletin of the World Health Organization 2001;79(8):704-12. [DOI: 10.1590/ S0042-96862001000800005]

\section{Weatherall 2006}

Weatherall D, Akinyanju O, Fucharoen S, Olivieri N, Musgrove P. Inherited disorders of hemoglobin. Disease Control Priorities in Developing Countries. 2nd Edition. Washington (DC): The World Bank and Oxford University Press, 2006:663-80.

\section{WHO 2010}

World Health Organization. Sickle-Cell Disease: A Strategy for the WHO African Region 2010. Regional Office for Africa http://www.afro.who.int/en/sixtieth-session.html (accessed 19 October 2015) 2010.

\section{WHO 2011}

World Health Organization. Sickle-cell disease and other haemoglobin disorders: Fact sheet $N^{\circ} 308$. World Health Organization, Media Centre January 2011:1-3. 
Wierenga 2001

Wierenga KJJ, Hambleton IR, Lewis NA. Survival estimates for patients with homozygous sickle-cell disease in Jamaica: a clinic-based population study. Lancet 2001;357(9257): 680-3. [DOI: 10.1016/S0140-6736(00)04132-5]

Wiffen 2005

Wiffen PJ, McQuay HJ, Edwards JE, Moore RA.

Gabapentin for acute and chronic pain. Cochrane Database of Systematic Reviews 2005, Issue 3. [DOI: 10.1002/ 14651858.CD005452]

\section{Yawn 2014}

Yawn BP, Buchanan GR, Afenyi-Annan AN, Ballas SK, Hassell KL, James AH, et al. Management of sickle cell disease: summary of the 2014 evidence-based report by expert panel members. JAMA 2014;312(10):1033-48. [DOI: 10.1001/jama.2014.10517]

* Indicates the major publication for the study

\section{A P P E N DICES}

\section{Appendix I. MEDLINE search strategy (via Ovid)}

1 exp Anemia, Sickle Cell/

2 sickle cell.tw.

3 "SCD".tw.

4 "sickling disorder".tw.

5 "HBS".tw.

6 (haemoglobin adj1 disease).tw.

7 (haemoglobin adj1 disease).tw.

8 or/ $1-7$

9 exp Pain/

10 pain*.tw.

$11 \mathrm{or} / 9-10$

12 (acetaminophen or "acetylsalicylic acid" or "alendronic acid" or alfentanil or amitriptyline or aspirin or baclofen or benzocaine or bupivacaine or buprenorphine or butorphanol or carbamazepine or chloroprocaine or "choline magnesium trisalicylate" or clonazepam or clonidine or codeine or dexamethasone or dexmetetomidine or dextroamphetamine or dextropropoxyphene or diamorphine or diazepam or diclofenac or dihydrocodeine or domperidone or fentanyl or fluoxetine or gabapentin or hydrocodone or hydromorphone or "hyoscine hydrobromide" or ibuprofen or ketamine or ketoprofen or ketorolac or "levo bupivacaine" or lidocaine or loperamide or lorazepam or mefenamic acid or meperidine or methadone or methylphenidate or midazolam or morphine or naproxen or nitrous oxide or nortriptyline or oxycodone or pamidronate or paracetamol or paroxetine or pentazocine or pethidine or phenobarbital or "phenytoin" or piroxicam or pregabalin or propoxyphene or "risedronate sodium" or "sodium clodronate" or tetracaine or tramadol or "valproic acid").tw.

13 exp Analgesics/

14 Anesthesia, Local/

15 exp Anti-Inflammatory Agents, Non-Steroidal/

16 or/12-15

178 and 11 and 16

18 randomized controlled trial.pt.

19 controlled clinical trial.pt.

Pharmacological interventions for painful sickle cell vaso-occlusive crises in adults (Protocol)

Copyright $\odot 2016$ The Cochrane Collaboration. Published by John Wiley \& Sons, Ltd. 
20 randomized.ab.

21 placebo.ab.

22 drug therapy.fs.

23 randomly.ab.

24 trial.ab.

25 groups.ab.

2618 or 19 or 20 or 21 or 22 or 23 or 24 or 25

27 exp animals/ not humans.sh.

2826 not 27

2917 and 28

\section{Appendix 2. EMBASE search strategy (via Ovid)}

1 exp Anemia, Sickle Cell/

2 sickle cell.tw.

3 “SCD”.tw.

4 "sickling disorder".tw.

5 "HBS".tw.

6 (haemoglobin adj1 disease).tw.

7 (haemoglobin adj1 disease).tw.

8 or/ $1-7$

9 exp Pain/

10 pain*.tw.

$11 \mathrm{or} / 9-10$

12 (acetaminophen or "acetylsalicylic acid" or "alendronic acid" or alfentanil or amitriptyline or aspirin or baclofen or benzocaine or bupivacaine or buprenorphine or butorphanol or carbamazepine or chloroprocaine or "choline magnesium trisalicylate" or clonazepam or clonidine or codeine or dexamethasone or dexmetetomidine or dextroamphetamine or dextropropoxyphene or diamorphine or diazepam or diclofenac or dihydrocodeine or domperidone or fentanyl or fluoxetine or gabapentin or hydrocodone or hydromorphone or "hyoscine hydrobromide" or ibuprofen or ketamine or ketoprofen or ketorolac or "levo bupivacaine" or lidocaine or loperamide or lorazepam or mefenamic acid or meperidine or methadone or methylphenidate or midazolam or morphine or naproxen or nitrous oxide or nortriptyline or oxycodone or pamidronate or paracetamol or paroxetine or pentazocine or pethidine or phenobarbital or "phenytoin" or piroxicam or pregabalin or propoxyphene or "risedronate sodium" or "sodium clodronate" or tetracaine or tramadol or "valproic acid").tw.

13 exp Analgesics/

14 Anesthesia, Local/

15 exp Anti-Inflammatory Agents, Non-Steroidal/

16 or/12-15

178 and 11 and 16

18 Randomized controlled trial/

19 Controlled clinical study/

2018 or 19

21 Random\$.ti,ab.

22 randomization/

23 intermethod comparison/

24 placebo.ti,ab.

25 (compare or compared or comparison).ti.

26 ((evaluated or evaluate or evaluating or assessed or assess) and (compare or compared or comparing or comparison)).ab.

27 (open adj label).ti,ab.

28 ((double or single or doubly or singly) adj (blind or blinded or blindly)).ti,ab.

29 double blind procedure/

30 parallel group $\$ 1 . t i, a b$.

31 (crossover or cross over).ti,ab.

Pharmacological interventions for painful sickle cell vaso-occlusive crises in adults (Protocol)

Copyright @ 2016 The Cochrane Collaboration. Published by John Wiley \& Sons, Ltd. 
32 ((assign $\$$ or match or matched or allocation) adj5 (alternate or group $\$ 1$ or intervention $\$ 1$ or patient $\$ 1$ or subject $\$ 1$ or participant\$1).ti,ab.

33 (assigned or allocated).ti,ab.

34 (controlled adj7 (study or design or trial)).ti,ab.

35 (volunteer or volunteers).ti,ab.

36 human experiment/

37 trial.ti.

38 or $/ 20-37$

3917 and 38

\title{
Appendix 3. CENTRAL search strategy (via CRSO)
}

\author{
\#1 MeSH DESCRIPTOR Anemia, Sickle Cell EXPLODE ALL TREES \\ \#2 (sickle cell):TI,AB,KY \\ \#3 “SCD”:TI,AB, KY \\ \#4 (“sickling disorder"):TI,AB,KY \\ \#5 “HBS”:TI,AB, KY \\ \#6 ((haemoglobin near1 disease)):TI,AB,KY \\ \#7 ((haemoglobin near1 disease)):TI,AB,KY \\ \#8 \#1 OR \#2 OR \#3 OR \#4 OR \#5 OR \#6 OR \#7 30 \\ \#9 MeSH DESCRIPTOR Pain EXPLODE ALL TREES \\ \#10 pain*:TI,AB,KY \\ \#11 \#9 OR \#10 \\ \#12 ((acetaminophen or "acetylsalicylic acid" or "alendronic acid" or alfentanil or amitriptyline or aspirin or baclofen or benzocaine or \\ bupivacaine or buprenorphine or butorphanol or carbamazepine or chloroprocaine or "choline magnesium trisalicylate" or clonazepam \\ or clonidine or codeine or dexamethasone or dexmetetomidine or dextroamphetamine or dextropropoxyphene or diamorphine or \\ diazepam or diclofenac or dihydrocodeine or domperidone or fentanyl or fluoxetine or gabapentin or hydrocodone or hydromorphone \\ or "hyoscine hydrobromide" or ibuprofen or ketamine or ketoprofen or ketorolac or "levo bupivacaine" or lidocaine or loperamide \\ or lorazepam or mefenamic acid or meperidine or methadone or methylphenidate or midazolam or morphine or naproxen or nitrous \\ oxide or nortriptyline or oxycodone or pamidronate or paracetamol or paroxetine or pentazocine or pethidine or phenobarbital or \\ "phenytoin" or piroxicam or pregabalin or propoxyphene or "risedronate sodium" or "sodium clodronate" or tetracaine or tramadol or \\ "valproic acid”)):TI,AB,KY \\ \#13 MeSH DESCRIPTOR Analgesics EXPLODE ALL TREES \\ \#14 MeSH DESCRIPTOR Anesthesia, Local \\ \#15 MeSH DESCRIPTOR Anti-Inflammatory Agents, Non-Steroidal EXPLODE ALL TREES \\ \#16 \#12 OR \#13 OR \#14 OR \#15 \\ \#17 \#8 AND \#11 AND \#16
}

\section{Appendix 4. LILACS search strategy}

(sickle cell) or SCD or (sickling disorder) or HBS or (haemoglobin disease) or (haemoglobin disease) [Words] and pain\$ [Words] and (acetaminophen or (acetylsalicylic acid) or (alendronic acid) or alfentanil or amitriptyline or aspirin or baclofen or benzocaine or bupivacaine or buprenorphine or butorphanol or carbamazepine or chloroprocaine or (choline magnesium trisalicylate) or clonazepam or clonidine or codeine or dexamethasone or dexmetetomidine or dextroamphetamine or dextropropoxyphene or diamorphine or diazepam or diclofenac or dihydrocodeine or domperidone or fentanyl or fluoxetine or gabapentin or hydrocodone or hydromorphone or (hyoscine hydrobromide) or ibuprofen or ketamine or ketoprofen or ketorolac or (levo bupivacaine) or lidocaine or loperamide or lorazepam or mefenamic acid or meperidine or methadone or methylphenidate or midazolam or morphine or naproxen or nitrous oxide or nortriptyline or oxycodone or pamidronate or paracetamol or paroxetine or pentazocine or pethidine or phenobarbital or (phenytoin) or piroxicam or pregabalin or propoxyphene or (risedronate sodium) or (sodium clodronate) or tetracaine or tramadol or (valproic acid)) [Words]

Pharmacological interventions for painful sickle cell vaso-occlusive crises in adults (Protocol) 


\section{CONTRIBUTIONSOFAUTHORS}

TC registered the title.

TC, IH, SB and PW wrote the 2016 protocol.

TC, IH, SB and PW will be responsible for the full review and subsequent updates.

\section{DECLARATIONSOF INTEREST}

TC: none known.

IH: none known.

SB is an internist specialising in basic and clinical haematology with an emphasis on the management of adult and paediatric patients with sickle cell disease and pain. During the last three years, SB has been in the Speakers Bureau of Novartis with an emphasis on Deferasirox (both Exjade and Jadenu formulations).

PW: none known.

\section{SOURCES OF SUPPORT}

\section{Internal sources}

- Oxford Pain Relief Trust, UK.

\section{External sources}

- The National Institute for Health Research (NIHR), UK.

Tess Cooper is funded part-time as a systematic reviewer from the PaPaS Group's NIHR Cochrane Programme Grant: 13/89/29 Addressing the unmet need of chronic pain: providing the evidence for treatments of pain 